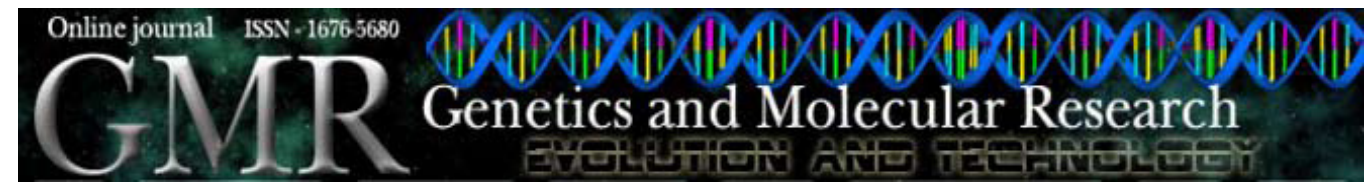

\title{
The monotony of transferrin and esterase electrophoretic patterns in pirarucu, Arapaima gigas (Schinz, 1822) from Santa Cruz Lake, Tefé River, Amazonas, Brazil
}

\author{
A.S. Teixeira \\ Instituto Nacional de Pesquisas da Amazônia (INPA), \\ Coordenação de Pesquisas em Biologia Aquática (CPBA), \\ Manaus, AM, Brasil \\ Corresponding author: A.S. Teixeira \\ E-mail: saturn@inpa.gov.br
}

Genet. Mol. Res. 7 (2): 407-416 (2008)

Received February 25, 2008

Accepted March 10, 2008

Published May 7, 2008

\begin{abstract}
Starch gel electrophoresis was used for examining the transferrin gene locus (Tf) and two esterase gene loci (Est-1 and Est-D1) of a pirarucu (Arapaima gigas) population sample collected from Santa Cruz Lake, Tefé River, Amazonas, Brazil. The Tf locus was tentatively classified as being polymorphic, showing two double-banded patterns $\left(\mathrm{Tf}^{12}\right.$ and $\left.\mathrm{Tf}^{22}\right)$ of the three theoretically expected ones $\left(\mathrm{Tf}^{11}, \mathrm{Tf}^{12}\right.$ and $\mathrm{Tf}^{22}$ ), presumably controlled by two co-dominant alleles, $\mathrm{Tf}^{1}$ and $\mathrm{Tf}^{2}$. The monotony detected in pirarucu Tf locus genotypes showing a very high proportion of the doublebanded heterozygote pattern $\mathrm{Tf}^{12}$ (95\% of the sampled individuals) may indicate the possibility of their having come from representatives of the same brood begotten by a pair of fish, where a single-banded $\mathrm{Tf}^{11}$ homozygote pattern male would have crossed with a singlebanded $\mathrm{Tf}^{22}$ homozygote pattern female, or vice versa. One zone
\end{abstract}


of electrophoretic activity was detected in esterase, presumably controlled by a monomorphic Est-1 locus with the fixed allele Est- $1^{1}$ where all individuals showed the single-banded Est- $1^{11}$ homozygote pattern. Esterase-D also displayed one zone of electrophoretic activity, presumably controlled by a monomorphic Est-D1 locus with a fixed allele Est-D $1^{1}$ where all individuals revealed the singlebanded Est-D $1^{11}$ genotype pattern. The monotony comprised by single-banded genotype patterns in both esterase systems tested may also indicate the possibility of the individuals from the sample examined having come from representatives of the same brood begotten by a pair of fish with both the male and female having the same genotypes.

Key words: Pirarucu; Amazon; Electrophoresis

\section{INTRODUCTION}

The family Arapaimatidae consists of only two species, the Neotropical arapaima, Arapaima gigas (Schinz, 1822), and the African bonytongue, Heterotis nilotticus, which in the recent past have often been placed within the family Osteoglossidae (Ferraris Júnior, 2003). Pirarucu is considered one of the largest freshwater scaled fish in the world, with adult individuals likely to surpass $2 \mathrm{~m}$ in length and often reach a weight of $125 \mathrm{~kg}$ or more (Goulding, 1980; Santos et al., 2006). This species displays a widespread geographical distribution in the Amazon, being one of the region's most important fishery resources and appearing among the world's most valuable freshwater fish species (see Queiroz and Sardinha, 1999). Presently, pirarucu is considered to be a vulnerable resource, due to being subjected to a heavy fishery effort since the early colonization of the Amazon region (Santos et al., 2006). Despite the legal measures already being taken for its protection, such as forbidding fishing them under gonadal maturation size, as well as banning their capture during their reproductive period (known in Brazil as defeso) (Queiroz and Sardinha, 1999), this species still continues to be exploited indiscriminately as seen by their sale in local fairs and markets the year round (Santos et al., 2006). Although it occupies a prominent position as one of the most landed species in several Amazon fishery harbors (see Queiroz and Sardinha, 1999), it is still not possible to determine its annual catch yields in tons in Brazil (Queiroz and Sardinha, 1999).

So far, little research has been carried out on pirarucu towards understanding its reproductive aspects. At first, research was only on individuals in captivity (Oliveira, 1944, cited by Imbiriba, 2001, p. 301; Fontenele, 1948, 1953). However, its reproductive behavior is quite complex involving the formation of monogamous couples and nest building, as well as offspring and nest parental care (Fontenele, 1948, 1953). For a more comprehensive review on this subject, see Imbiriba (2001).

In addition to the above research, other studies on pirarucu have been carried out in the Mamirauá Sustainable Development Reserve in the State of Amazonas, on preservation and sustainability (Queiroz and Sardinha, 1999) and yielding system in captivity (Imbiriba, 2001). More recently, there have been other studies on population genetics, 
based on mitochondrial DNA sequences (Hrbek et al., 2005), gonadal morphology and reproductive traits (Godinho et al., 2005), feeding analyses (Olivera et al., 2005), and mitotic chromosomes (Marques et al., 2006), in wild-fish samples from several sites in the Amazon region. All of these studies without exception have yielded valuable information for the management and conservation policies of this species.

There is a pressing need for generating information concerning the most diverse types of pirarucu protein and enzyme variants, to be used as an important tool in detecting and defining independent pirarucu fish stocks in the Amazon; this is also applicable to all other commercial fish species in the region. Thus, a thorough knowledge regarding allele frequency distributions with possible detection of statistical deviations (significant genetic heterogeneity among the population samples examined) in the most varied pirarucu protein and isoenzyme markers is a basic requirement for attaining this objective.

Due to the simplicity of inheritance and the low coefficients of selection, the codominant alleles which segregate at the transferrin single gene locus (Tf) can be widely used as genetic markers (Monostory et al., 1984). On account of demonstrating a high evolutionary change rate in its molecular structure and a high degree of genetic polymorphism in many vertebrate species, the Tf gene locus has been very helpful in studies regarding the characterization of population genetic structure for several commercial fish species, mainly the marine ones (Jamieson and Turner, 1978; Jamieson and Birley, 1989). The distributions of genotypes and alleles at that locus have already provided some information on the population genetic structure of Amazonian aquatic species, such as tambaqui, Colossoma macropomum, in a native population (Teixeira and Jamieson, 1985) and hatchery stocks (Calcagnotto and Toledo-Filho, 2000), two jaraqui species, Semaprochilodus taeniurus and S. insignis (Teixeira et al., 1990), one turtle species, Podocnemis expansa (Teixeira et al., 1996), and one pescada species, Plagioscion squamosissimus (Teixeira et al., 2002). However, at the moment there is no available information on electrophoretic Tf locus genotypes, applied to the study of pirarucu and its natural stocks.

The high degree of polymorphism at their gene loci in a large number of organisms of the most varied species stands out among the main advantages shown by the esterase enzymes (Ferguson, 1980). Apart from recent evidence identifying a supposed natural hybrid of peacock bass (Teixeira and Oliveira, 2005) and a preliminary investigation on the Central Amazon piranha (Teixeira et al., 2006), no other data on Amazonian fish esterase loci based on electrophoretic patterns have yet been published.

The present paper reports, for the first time, data on transferrin and esterase genotype patterns of pirarucu. It also discusses the possibility of the sampled material caught from Santa Cruz Lake, Tefé River, Amazonas, Brazil, as having originated from representatives of the same brood.

\section{MATERIAL AND METHODS}

A population sample of pirarucu (Arapaima gigas) comprised of 19 juvenile specimens was collected at Santa Cruz Lake, Tefé River, Amazonas, Brazil, in September 2001 (Figure 1). All the fish were caught together at a confined site, i.e., in a stretch of Santa Cruz Lake that was totally isolated from the main lake on account of the low water period. 

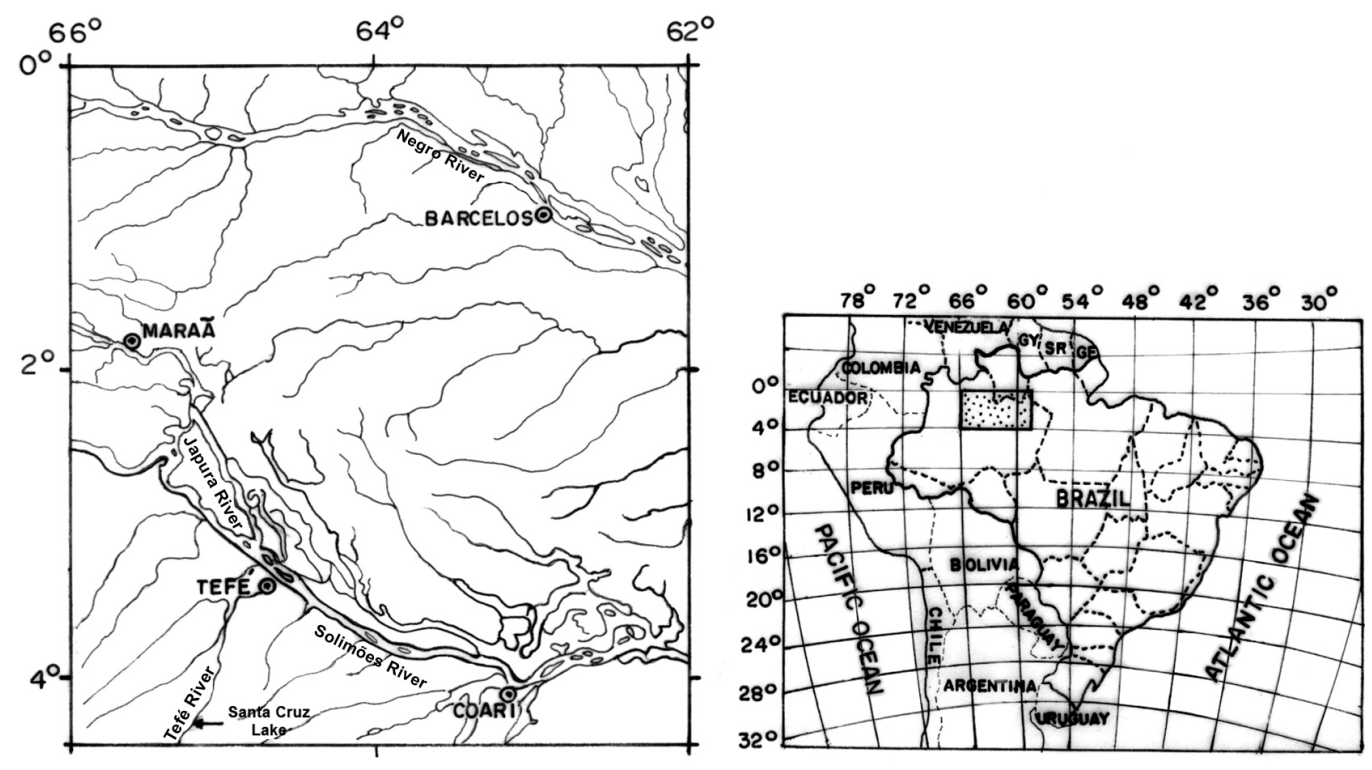

$30 \mathrm{~km} 150306090120150180210240270300 \mathrm{~km}$

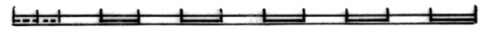

Figure 1. Collecting site of pirarucu (Arapaima gigas) population sample, at Santa Cruz Lake, Tefé River, Amazonas, as indicated by the arrow.

The starch-gel electrophoresis technique was used to analyze the transferrin (Tf) gene locus in blood plasma samples and two loci of esterases (Est-1 and Est-D1) detected in skeletal muscle protein extracts, from the above pirarucu specimens. The differential precipitation method with rivanol described by Jamieson and Turner (1978) was used for isolating blood plasma transferrin prior to the electrophoretic tests. The gel buffer was prepared with $0.03 \mathrm{M}$ Tris (hydroxymethyl-aminomethane) and $0.005 \mathrm{M}$ citric acid, and the electrode buffer with $0.06 \mathrm{M}$ lithium hydroxide and $0.30 \mathrm{M}$ boric acid, according to the method described by Ridgway et al. (1970), both for transferrin and esterases. Sigma starch at $13 \%$, dissolved in $280 \mathrm{~mL}$ of the gel buffer containing $2.80 \mathrm{~mL}$ of the electrode buffer, was used for preparing the gels. The starch suspension was heated to the boiling point in a two-liter round-bottomed flask resting on a heating mantle, using continuous shaking with the aid of a mechanical shaker. The protein supernatants were absorbed on $8 \mathrm{~mm} \times 6 \mathrm{~mm}$ Whatman filter papers which were then inserted along a slot cut into each slab of gel approximately $4 \mathrm{~cm}$ from the cathodic wick end. For the analysis of the esterases, the gel was submitted to $150 \mathrm{~V}$ for the initial $45 \mathrm{~min}$. The paper inserts were then removed and the electrophoretic run continued for $4 \mathrm{~h}$. For the transferrin analysis, the gel was submitted to $125 \mathrm{~V}$ for the initial $45 \mathrm{~min}$. The paper inserts were then removed and the electrophoretic run continued at $225 \mathrm{~V}$ for approximately $3 \mathrm{~h}$ and $30 \mathrm{~min}$ more. Electrophoretic migrations both for transferrin and esterases took place towards the anode. Gel staining for transferrin was done with $1 \%$ amido black for 5 min (Jamieson and Turner, 1978) and its destaining lasted for nearly $15 \mathrm{~h}$ (Teixeira et al., 1996). $\alpha$-Naphthyl 
acetate was used as the substrate for esterase staining according to the method described by Shaw and Prasad (1970), whereas the 4-methyl umbelliferyl acetate was the substrate for esterase-D staining according to the method described by Hopkinson et al. (1973).

\section{RESULTS}

\section{Transferrins}

The transferrin gene locus (Tf) in the pirarucu (Arapaima gigas) population sample was tentatively classified as being polymorphic with the presence of two double-banded genotypes $\left(\mathrm{Tf}^{12}\right.$ and $\mathrm{Tf}^{22}$ ) (Figure 2, Table 1) of the three theoretically expected ones $\left(\mathrm{Tf}^{11}, \mathrm{Tf}^{12}\right.$ and $\mathrm{Tf}^{22}$ ) presumably controlled by two co-dominant alleles, $\mathrm{Tf}^{1}$ and $\mathrm{Tf}^{2}$. Nevertheless, definition of the gene control mechanism enabling a precise calculation of allele frequencies at the Tf locus in this species would only have been possible if population samples comprised of individuals with $\mathrm{Tf}^{11}, \mathrm{Tf}^{12}$ and $\mathrm{Tf}^{22}$ genotypes were found in nature, segregating the two detected co-dominant alleles $\mathrm{Tf}^{1}$ and $\mathrm{Tf}^{2}$, following the Mendelian rules of inheritance.

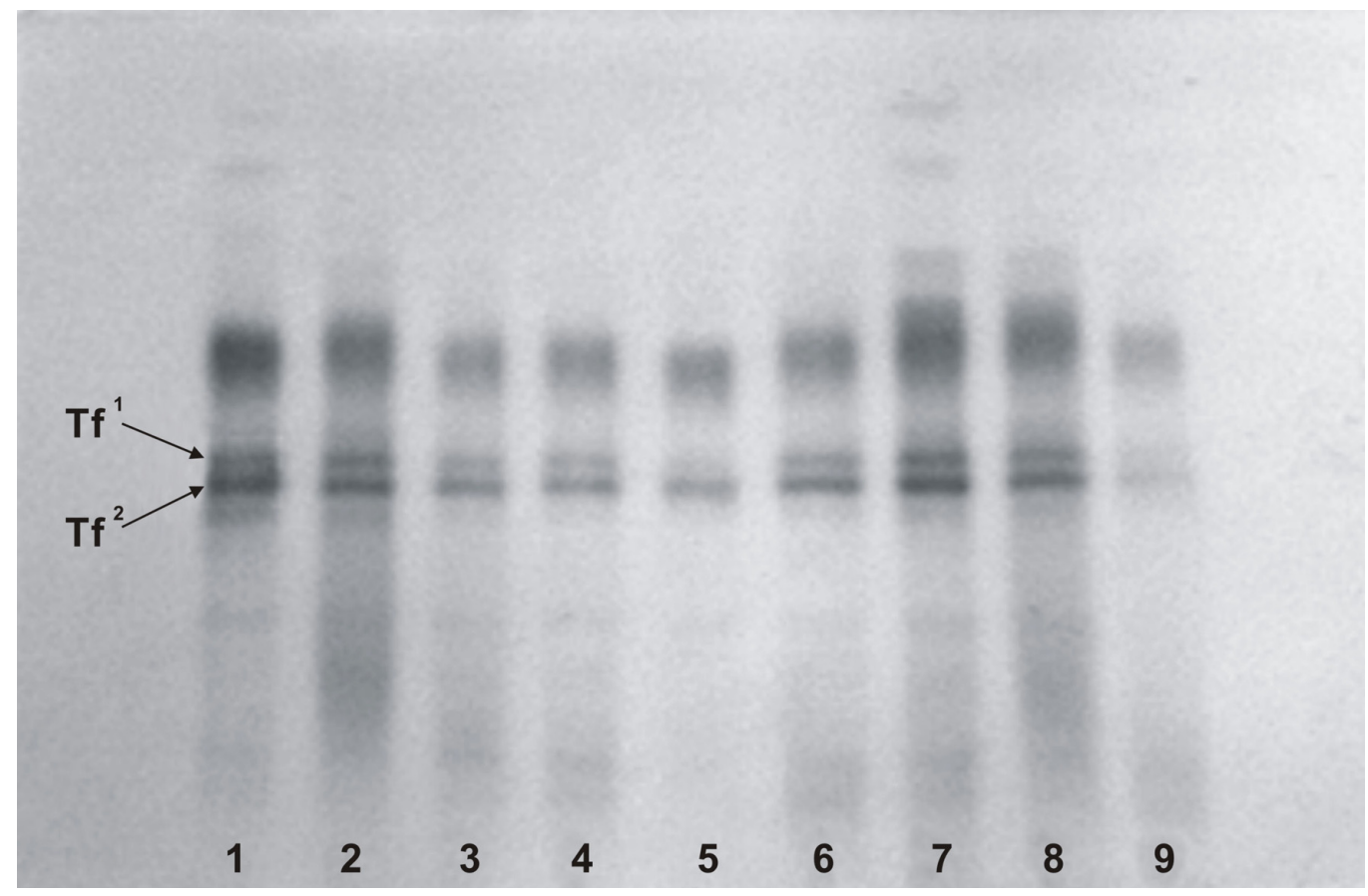

Figure 2. Transferrin genotypes shown by starch gel electrophoresis technique on a population sample of pirarucu (Arapaima gigas), collected at Santa Cruz Lake, Tefé River, Amazonas. In this gel the number 5 profile represents the single banded $\mathrm{Tf}^{22}$ homozygote individual found in the sample, whereas the other specimens represent the $\mathrm{Tf}^{12}$ heterozygote individuals. 
Table 1. Genotype distribution observed in transferrin (Tf), esterase (Est-1) and esterase-D (Est-D1) loci in one population sample of pirarucu (Arapaima gigas) collected at Santa Cruz Lake, Tefé River, Amazonas.

\begin{tabular}{lc}
\hline Genotype & Observed \\
\hline $\mathrm{Tf}^{11}$ & 0 \\
$\mathrm{Tf}^{12}$ & 18 \\
$\mathrm{Tf}^{22}$ & 1 \\
Est- $^{11}$ & 19 \\
Est-D1 $^{11}$ & 19 \\
\hline
\end{tabular}

The pirarucu reproductive behavior involving the formation of monogamous pairs during the species' mating and spawning period (Fontenele, 1948, 1953), may explain the monotony displayed by its $\mathrm{Tf}$ locus genotypes which showed a very high proportion of the double-banded heterozygote pattern $\mathrm{Tf}^{12}$ ( $95 \%$ of the sampled individuals), i.e., 18 of 19 fishes examined (Table 1), therefore indicating the possibility of their having come from representatives of the same brood begotten by a pair of fish, where a single-banded $\mathrm{Tf}^{11}$ homozygote pattern male would have crossed with a single-banded $\mathrm{Tf}^{22}$ homozygote pattern female, or vice versa. Yet, a theoretically expected double-banded $\mathrm{Tf}^{12}$ heterozygote pattern would also be possible, if the sampling individuals had been begotten by a pair of fish with both the male and female involved in three more possible types of mating $\left(\mathrm{Tf}^{12} v s \mathrm{Tf}^{12} ; \mathrm{Tf}^{12} v s \mathrm{Tf}^{11}\right.$, and $\mathrm{Tf}^{12} v s \mathrm{Tf}^{22}$ ) (Table 2). The singlebanded $\mathrm{Tf}^{22}$ homozygote individual pattern detected in the sample may be considered as fortuitous, presumably generated by a different pair of fish with the male and female having the same single-banded $\mathrm{Tf}^{22}$ homozygote pattern, or by a pair of fish with the male and female involved in two more types of mating $\left(\mathrm{Tf}^{12} v s \mathrm{Tf}^{22}\right.$ and $\left.\mathrm{Tf}^{12} v s \mathrm{Tf}^{12}\right)$. This deflected single-banded $\mathrm{Tf}^{22}$ homozygote fish in the sample is within the expected statistical error margin, i.e., $5 \%$. This individual may be taken for what we usually call "the odd one in the nest". Other indications that the majority of the individuals examined might have originated from a single offspring are the size and weight classes of the individuals that show quite close values, ranging from $61-72 \mathrm{~cm}(67.84$ $\pm 3.087)$ and $1.93-4.0 \mathrm{~kg}(3.05 \pm 0.526)$, respectively. Furthermore, the only $\mathrm{Tf}^{22}$ fish found in the sample, the smallest size $(61 \mathrm{~cm})$ and weight $(1.93 \mathrm{~kg})$ compared to the others, may be explained as possibly having come from another cohort. Yet, one cannot discard the possibility of this single $\mathrm{Tf}^{22}$ homozygote fish as being found in the sample as result of an extra-pair paternity. In avian mating systems, the application of molecular genetic techniques has revealed, contrary to prior expectations, that birds are rarely sexually monogamous, with extra-pair offspring found in approximately $90 \%$ of species, i.e., cuckoldry (Griffith et al., 2002).

Table 2. Observed and expected genotype proportions at the transferrin gene locus (Tf) in all theoretically possible types of mating in pirarucu.

\begin{tabular}{|c|c|c|c|c|c|c|}
\hline \multirow[t]{3}{*}{ Type of mating } & \multicolumn{6}{|c|}{ Progeny genotypes } \\
\hline & \multicolumn{2}{|c|}{$\mathrm{Tf}^{11}$} & \multicolumn{2}{|c|}{$\operatorname{Tf}^{12}$} & \multicolumn{2}{|c|}{$\mathrm{Tf}^{22}$} \\
\hline & Observed & Expected & Observed & Expected & Observed & Expected \\
\hline $\operatorname{Tf}^{11} v s \operatorname{Tf}^{22}$ & 0.00 & 0.00 & 0.95 & 1.00 & 0.05 & 0.00 \\
\hline $\operatorname{Tf}^{12} v s \operatorname{Tf}^{12}$ & 0.00 & 0.25 & 0.95 & 0.50 & 0.05 & 0.25 \\
\hline $\operatorname{Tf}^{12} v s \operatorname{Tf}^{11}$ & 0.00 & 0.50 & 0.95 & 0.50 & 0.05 & 0.00 \\
\hline $\mathrm{Tf}^{12} v s \mathrm{Tf}^{22}$ & 0.00 & 0.00 & 0.95 & 0.50 & 0.05 & 0.50 \\
\hline $\operatorname{Tf}^{11}$ vs $\operatorname{Tf}^{11}$ & 0.00 & 1.00 & 0.95 & 0.00 & 0.05 & 0.00 \\
\hline $\operatorname{Tf}^{22} v s \operatorname{Tf}^{22}$ & 0.00 & 0.00 & 0.95 & 0.00 & 0.05 & 1.00 \\
\hline
\end{tabular}




\section{Esterases}

One zone of electrophoretic activity was detected in pirarucu esterase, presumably expressed by the action of a monomorphic Est-1 locus, which showed the fixed allele Est- $1^{1}$, where all 19 individuals analyzed exhibited a single-banded Est- $1^{11}$ homozygote pattern (Table 1). Esterase-D also presented one zone of electrophoretic activity supposedly expressing the action of a monomorphic Est-D1 locus, with a fixed allele Est-D 1', where all 19 individuals exhibited a single-banded Est-D $1^{11}$ homozygote pattern (Table 1). The monotony shown by single-banded genotype patterns revealing just homozygote individuals in pirarucu esterases (Est- $1^{11}$ and Est-D ${ }^{11}$ ) may also indicate the possibility of the individuals sampled having come from representatives of the same brood begotten by a single pair of fish, with the male and female possessing the same homozygote patterns. Apart from the above fish sample examined, three extra pirarucu adult specimens collected from the Mamirauá Sustainable Development Reserve, when screened for esterase and esterase-D, also displayed the same single-banded esterase homozygote patterns (Teixeira AS, unpublished data). Moreover, the finding of the deflected fish, i.e., the one with smallest size and weight in the sample (see transferrin results), showing the same single-banded esterase homozygote pattern, may reinforce the assumption of Est-1 and Est-D1 as being monomorphic loci in the species as a whole. Nevertheless, other possibilities of the pirarucu offspring showing the same single-banded genotype pattern for these two esterase enzymes screened here, or for any other protein and/or enzyme system to be examined, would be possible if a given pirarucu sample was begotten by a single pair of fish with the male and female possessing the same allele of any polymorphic locus (homozygote genotype male would have crossed with a heterozygote genotype female, or vice versa; or a heterozygote genotype male crossed with a heterozygote genotype female, or vice versa).

\section{DISCUSSION}

Social monogamy, especially in birds, does occur where a species forms a pair bond but may participate in copulations outside the pair bond, while genetic monogamy does occur where individuals participate only in copulations within a pair bond (see Taylor et al., 2003). According to these authors, genetic monogamy is rare in fish with only a few available records in the literature. Nevertheless, when this phenomenon does happen in fish, it is usually connected with social monogamy (e.g., due to a need for biparental defense of territories and/or care of offspring) (see Chapman et al., 2004). Microsatellite loci as markers can be useful for testing if social monogamy predicts genetic monogamy, as recently demonstrated in the largemouth bass Micropterus salmoides (DeWoody et al., 2000). Using the above types of markers for genotyping parents and offspring, Taylor et al. (2003) suggested that the biparental mouthbrooding cichlid fish, Eretmodus cyanostictus, from Lake Tanganyika, Africa, is both socially and genetically monogamous.

Although the pirarucu is widely accepted as showing monogamous behavior, up to now there are no reproductive data available in the current literature which show with certainty, whether or not this species displays social monogamy or genetic monogamy. Therefore, the present genetic findings point to the urgent need for future simultaneous research on genetics and ecology, with field observations of the monogamous behavior of pirarucu. In this respect, I absolutely agree with DeWoody (2005) who said, "as science becomes more integrative and complex, it is easy to envision a future where collaborations between geneticists (who may 
not have the expertise to obtain the field samples) and wildlife biologists (who may not have the expertise and/or facilities to obtain the genotypes) are common and serve to answer both fundamental and applied questions".

The application of autosomal co-dominant polymorphic gene loci, which may show a series of segregating alleles when analyzed by electrophoretic techniques, should be extremely useful for solving problems concerning animal parentage and sibship (Jamieson, 1994). This author skilfully demonstrated the application of two general formulae developed for testing parentage and distinguishing sibs in natural random-mating populations, isolated subpopulations, or domesticated breeds. Thus, analysis of parentage based on single-locus polymorphisms, such as the transferrin (Tf) gene locus which is widely known to show a high degree of genetic polymorphism, displaying a series of autosomal co-dominant alleles in many vertebrate species, especially in fish (Jamieson and Turner, 1978; Monostory et al., 1984; Teixeira and Jamieson, 1985; Jamieson and Birley, 1989; Teixeira et al., 1990; Teixeira et al., 2002), and apparently appearing to be polymorphic in pirarucu, may be very important in defining whether this species displays social or genetic monogamy.

The usefulness of several molecular approaches and techniques for undertaking parentage analysis has recently been reviewed (Jones and Ardren, 2003; DeWoody, 2005) and appears to be extremely useful in answering innumerous questions concerned with wildlife and fishery biology.

There are continuing signs of the potential threat to pirarucu survival. The populations of this species around major Amazonian cities and in the center of its distribution are genetically depleted, and the entire population is in genetic disequilibrium (Hrbek et al., 2005). Therefore, it is advisable that population genetic analyses, using different types of genetic molecular markers, complemented with other fishery biology approaches, be urgently considered for practical management and future conservation of the species. Nevertheless, due to the monogamous behavior of pirarucu (Fontenele, 1948, 1953), the definition of electrophoretic genotype patterns of Tf, Est-1, Est-D1 or of any other proteinisoenzyme marker to be included in future gene surveys, with the purpose of examining the population genetic structure of this species, will only be possible using adult fish population samples from different areas in the Amazon leaving out the brood. Pirarucu juveniles caught together may be the offspring of a unique pair of fish, in which case the sample will certainly not be representative material for the total river population of this species.

Our continuing aim is to find appropriate examples of protein and enzyme variant genes, which conveniently diagnose pirarucu and its genetic stocks, to help in the long-term management of this species in the Amazon region.

\section{ACKNOWLEDGMENTS}

The author is indebted to the late Mr. Sigueru Alfaia Esashika for catching fish samples, Mr. Raimundo Sotero da Silva for helping during the collection of muscle and blood samples, and Mr. George Nakamura for revising the preliminary English version of the manuscript. Research partially supported by the National Research Institute of Amazonia (INPA), through the Institutional Project Programme (PPI 1-3090) and by Agencia Española de Cooperación Inernacional (AECI). 


\section{REFERENCES}

Calcagnotto D and Toledo-Filho SA (2000). Loss of genetic variability at the transferrin locus in five hatchery stocks of tambaqui (Colossoma macropomum). Genet. Mol. Biol. 23: 127-130.

Chapman DD, Prodöhl PA, Gelsleichter J, Manire CA, et al. (2004). Predominance of genetic monogamy by females in a hammerhead shark, Sphyrna tiburo: implications for shark conservation. Mol. Ecol. 13: 1965-1974.

DeWoody JA (2005). Molecular approaches to the study of parentage, relatedness and fitness: practical applications for wild animals. J. Wildl. Manage. 69: 1400-1418.

DeWoody JA, Fletcher DE, Wilkins SD, Nelson WS, et al. (2000). Genetic monogamy and biparental care in an externally fertilizing fish, the largemouth bass (Micropterus salmoides). Proc. Biol. Sci. 267: 2431-2437.

Ferguson A (1980). Biochemical systematics and evolution. Blackie Son Limited, Glasgow.

Ferraris CJ Jr (2003). Family Arapaimatidae. In: Check list of the freshwater fishes of South and Central America (Reis RE, Kullander SO and Ferraris CJ Jr, eds.). EDIPUCRS, Porto Alegre, 31-32.

Fontenele O (1948). Contribuição para o conhecimento da Biologia do Pirarucu, Arapaima gigas (Cuvier), em cativeiro (Actinopterygii, Osteoglossidae). Rev. Bras. Biol. 8: 445-459.

Fontenele O (1953). Hábitos de desova do pirarucu Arapaima gigas (Cuvier) (Pisces: Isospondyli, Arapaimidae), e evolução da sua larva. Bol. Tec. DNOCS, 153 (Series I-C), Fortaleza, 1-22.

Godinho HP, Santos JE, Formagio PS and Guimarães-Cruz RJ (2005). Gonadal morphology and reproductive traits of the Amazonian fish Arapaima gigas (Schinz, 1822). Acta Zool. 86: 289-294.

Goulding M (1980). The Fishes and the Forest: Explorations in Amazonian Natural History. University of California Press, Los Angeles.

Griffith SC, Owens IP and Thuman KA (2002). Extra pair paternity in birds: a review of interspecific variation and adaptive function. Mol. Ecol. 11: 2195-2212.

Hopkinson DA, Mestriner MA, Cortner J and Harris H (1973). Esterase D: a new human polymorphism. Ann. Hum. Genet. 37: 119-137.

Hrbek T, Farias IP, Crossa M, Sampaio I, et al. (2005). Population genetic structure of Arapaima gigas, world's biggest freshwater fish: implications for conservation. Anim. Conserv. 8: 297-308.

Imbiriba EP (2001). Potencial de criação de pirarucu, Arapaima gigas, em cativeiro. Acta Amazon. 31: 299-316.

Jamieson A (1994). The effectiveness of using co-dominant polymorphic allelic series for (1) checking pedigrees and (2) distinguishing full-sib pair members. Anim. Genet. 25 (Suppl) 1: 37-44.

Jamieson A and Turner RJ (1978). The extended series of Tf alleles in Atlantic cod, Gadus morhua. In: Marine Organisms (Battaglia B and Beardmore JA, eds.). Plenum Publishing Corporation, New York, 699-729.

Jamieson A and Birley AJ (1989). The distribution of transferrin alleles in haddock stocks. J. Marine Sci. 45: 248-262.

Jones AG and Ardren WR (2003). Methods of parentage analysis in natural populations. Mol. Ecol. 12: 2511-2523.

Marques DK, Venere PC and Galetti PM Jr (2006). Chromosomal characterization of the bonytongue Arapaima gigas (Osteoglossiformes: Arapaimidae). Neotrop. Ichthyol. 4: 215-218.

Monostory Z, Nagy A, Gervai J and Csanyi V (1984). Polymorphism and inheritance of serum esterases and beta-globulins in the paradise fish (Macropodus opercularis; Anabantidae). Anim. Blood Groups Biochem. Genet. 15: 1-11.

Oliveira V, Poleto SL and Venere PC (2005). Feeding of juvenile pirarucu (Arapaima gigas, Arapaimidae) in their natural environment, lago Quatro Bocas, Araguaiana-MT, Brazil. Neotrop. Ichthyol. 3: 312-314.

Queiroz HL and Sardinha AD (1999). A preservação e o uso sustentado dos pirarucus (Arapaima gigas, Osteoglossidae) em Mamirauá. In: Estratégias para Manejo de Recursos Pesqueiros em Mamirauá. SCM, CNPq/MCT, Brasília, 108-141.

Ridgway GJ, Sherburne SW and Lewis RD (1970). Polymorphism in the esterases of Atlantic herring. Trans. Am. Fish. Soc. 99: 147-151.

Santos GM, Ferreira EJG and Zuanon JAS (2006). Peixes comerciais de Manaus. IBAMA/PROVÁRZEA, Manaus.

Shaw CR and Prasad R (1970). Starch gel electrophoresis of enzymes - a compilation of recipes. Biochem. Genet. 4: 297-320.

Taylor MI, Morley JI, Rico C and Balshine S (2003). Evidence for genetic monogamy and female-biased dispersal in the biparental mouthbrooding cichlid Eretmodus cyanostictus from Lake Tanganyika. Mol. Ecol. 12: 3173-3177.

Teixeira AS and Jamieson A (1985). Genetic variation in plasma transferrins of tambaqui, Colossoma macropomum (Cuvier, 1818). Amazoniana 9: 159-168.

Teixeira AS and Oliveira SS (2005). Evidence for a natural hybrid of peacock bass (Cichla monoculus vs Cichla temensis) based on esterase electrophoretic patterns. Genet. Mol. Res. 4: 74-83.

Teixeira AS, Raposo JCP and Jamieson A (1990). Transferrin variation in jaraquis, Semaprochilodus taeniurus and $S$. 
insignis, in the Amazon region. Anim. Genet. 21: 419-422.

Teixeira AS, Jamieson A, Raposo JCP and Vieira AA (1996). Transferrin polymorphism in Amazon turtle (Podocnemis expansa) stocks. Braz. J. Genet. 19: 559-564.

Teixeira AS, Jamieson A and Raposo JC (2002). Transferrin polymorphism in Central Amazon populations of pescada, Plagioscion squamosissimus. Genet. Mol. Res. 1: 216-226.

Teixeira AS, Nakayama CM, Porto JIR and Feldberg E (2006). Esterase-D and chromosome patterns in Central Amazon piranha (Serrasalmus rhombeus Linnaeus, 1766) from Lake Catalão. Genet. Mol. Biol. 29: 498-502. 